\title{
Hereditary Hepatic and Systemic Amyloidosis Caused by a New Deletion/Insertion Mutation in the Apolipoprotein Al Gene
}

\author{
David R. Booth, ${ }^{\star}$ Si-Yen Tan, ${ }^{\star}$ Susanne E. Booth, ${ }^{\star}$ Glenys A. Tennent, ${ }^{\star}$ Winston L. Hutchinson, ${ }^{\star}$ J. Justin Hsuan, ${ }^{\S}$ \\ Nicholas F. Totty, ${ }^{\S}$ Oanh Truong, ${ }^{\S}$ Anne K. Soutar, ${ }^{\star}$ Philip N. Hawkins, ${ }^{*}$ Miquel Bruguera, " Joan Caballería," Manel Solé, ${ }^{\star \star}$ \\ Josep M. Campistol, ${ }^{\ddagger}$ and Mark B. Pepys* \\ *Immunological Medicine Unit, Department of Medicine, and ${ }^{\ddagger}$ Medical Research Council Lipoprotein Team, Clinical Sciences Centre, \\ Royal Postgraduate Medical School, Hammersmith Hospital, London W12 0NN; ${ }^{\S}$ Ludwig Institute for Cancer Research, University \\ College London School of Medicine, London W1P 8BT; "Department of Biochemistry and Molecular Biology, University College \\ London, London WC1E 6BT, United Kingdom; and ${ }^{\llbracket}$ Liver Unit, ${ }^{* *}$ Pathology Department, and ${ }^{\ddagger}$ Renal Transplant Unit, Hospital Clinic, \\ University of Barcelona, 08036-Barcelona, Spain
}

\begin{abstract}
We report a Spanish family with autosomal-dominant nonneuropathic hereditary amyloidosis with a unique hepatic presentation and death from liver failure, usually by the sixth decade. The disease is caused by a previously unreported deletion/insertion mutation in exon 4 of the apolipoprotein AI (apoAI) gene encoding loss of residues 60-71 of normal mature apoAI and insertion at that position of two new residues, ValThr. Affected individuals are heterozygous for this mutation and have both normal apoAI and variant molecules bearing one extra positive charge, as predicted from the DNA sequence. The amyloid fibrils are composed exclusively of $\mathrm{NH}_{2}$-terminal fragments of the variant, ending mainly at positions corresponding to residues 83 and 92 in the mature wild-type sequence. Amyloid fibrils derived from the other three known amyloidogenic apoAI variants are also composed of similar $\mathrm{NH}_{2}$-terminal fragments. All known amyloidogenic apoAI variants carry one extra positive charge in this region, suggesting that it may be responsible for their enhanced amyloidogenicity. In addition to causing a new phenotype, this is the first deletion mutation to be described in association with hereditary amyloidosis and it significantly extends the value of the apoAI model for investigation of molecular mechanisms of amyloid fibrillogenesis. (J. Clin. Invest. 1996. 97:27142721.) Key words: amyloidosis • apolipoprotein AI • gene • liver • mutation
\end{abstract}

\section{Introduction}

Hereditary amyloidosis is an autosomal-dominant condition caused by point mutations in the genes encoding a variety of different proteins (reviewed in reference 1). These mutations produce single-residue substitutions in the mature protein that lead to the whole molecule, or a proteolytic cleavage fragment being deposited extracellularly in the tissues as insoluble amyloid fibrils that accumulate and cause organ dysfunction pre-

Address correspondence to Mark B. Pepys, Immunological Medicine Unit, Department of Medicine, Royal Postgraduate Medical School, Hammersmith Hospital, Du Cane Road, London W12 0NN. Phone: 44-81-740-3202; FAX: 44-81-749-7478; E-mail: mpepys@rpms.ac.uk

Received for publication 29 January 1996 and accepted 8 March 1996.

J. Clin. Invest.

(C) The American Society for Clinical Investigation, Inc. 0021-9738/96/06/2714/08 \$2.00

Volume 97, Number 12, June 1996, 2714-2721 senting in adult life. Mutations in the gene for $\beta$-amyloid precursor protein cause amyloid deposition that is confined to the brain in familial Alzheimer's disease $(2,3)$, and in hereditary cerebral hemorrhage with amyloidosis (Dutch type) (4). However, in all other forms of hereditary amyloidosis, the deposits are systemic even though the clinical presentation is usually dominated by manifestations in particular organ systems. Mutations in some genes cause very specific patterns of disease, such as hereditary cerebral hemorrhage with amyloidosis (Icelandic type), associated with variant cystatin C (5) and Finnish familial amyloidosis, associated with variants of gelsolin $(6,7)$. Mutations in the genes for other amyloidogenic proteins cause varied and overlapping clinical syndromes unrelated to the protein involved, and the same mutation can produce a different phenotype in different families and even between members of the same family. This is the case in familial amyloid polyneuropathy, the commonest form of hereditary amyloidosis, which can be caused by more than 50 different point mutations in the transthyretin gene (8), and in hereditary nonneuropathic amyloidosis which can be caused by mutations in the genes for apoAI (9-12), lysozyme (13), and fibrinogen $\alpha$-chain $(14,15)$. Although the most common amyloidogenic transthyretin variant, Met30Val, does not always cause disease, all the amyloidogenic mutations in other genes seem to be completely penetrant. Nevertheless, there evidently are other genetic and/or environmental factors unrelated to the amyloid fibril protein itself that contribute to deposition of amyloid and its clinical effects.

Apart from their intrinsic interest and the clinical significance for the rare affected kindreds, the hereditary amyloidoses provide valuable models for analyzing the pathogenesis of the common acquired forms of amyloidosis. The most important of these is Alzheimer's disease, the fourth most common cause of death in the western world, and the discovery that mutations in the gene-encoding $\beta$-amyloid precursor protein can cause early onset of familial Alzheimer's has already revolutionized work on this condition $(2,3)$. Furthermore, elucidation of the molecular basis of amyloid-fibril formation, which should be facilitated by study of the amyloidogenic variant proteins, may permit rational approaches to therapy. The lysozyme mutations that cause nonneuropathic amyloidosis (13) are particularly promising because all aspects of the structure and folding of this protein are so well characterized. However, apoAI offers a different but very intriguing challenge because, although its wild-type crystal structure has not yet been determined, all three amyloidogenic variants contain arginine substitutions for neutral residues within the $\mathrm{NH}_{2}$-terminal region of the molecule, and it is this fragment that forms the amyloid fibrils $(10,12,16,17)$. None of the other known apoAI 
variants are amyloidogenic (18). We report here a family with hereditary nonneuropathic amyloidosis caused by a new apoAI variant, in which 12 residues in the amyloidogenic $\mathrm{NH}_{2}$-terminal fragment have been deleted and 2 residues inserted. This is the first deletion mutation in any gene associated with hereditary amyloidosis but, most importantly, it produces an extra positive charge, suggesting that acquisition of such a charge in this part of the apoAI molecule, rather than substitution by any specific residue, may be the key amyloidogenic change.

\section{Methods}

Patients. An extended kindred from Cerdanya, Catalonia, Spain, was identified with a high incidence of systemic amyloidosis presenting with slowly progressive and uniformly fatal liver involvement. The diagnosis of amyloidosis was first made in two asymptomatic female first cousins (Fig. 1) with abnormal liver function tests detected during routine screening at ages 60 and 55, and in whom liver biopsies were then undertaken. Subsequently, the male proband for the present study (Fig. 1), in whom chronic liver disease had been diagnosed at age 40 , presented at age 61 with bleeding esophageal varices and rapidly developed fatal hepatic encephalopathy.

Clinical investigations. All clinical chemistry, plasma lipid and lipoprotein analyses, and histological examinations were performed by standard procedures. Amyloid deposits were identified histologically by green birefringence in polarized light after Congo red staining (19).

Identification, isolation, and characterization of amyloid fibrils. Fresh frozen, unfixed tissue obtained at autopsy of the proband was examined by immunohistochemical staining precisely as described previously $(11,20)$. Amyloid fibrils were isolated from fragments of spleen, liver, kidney, and heart by the water extraction method (21) as lately modified for very small tissue samples (22). Their protein subunits were separated in reduced SDS-PAGE, and subjected to au- tomated amino acid-sequence analysis, as previously described (10, 23). The subunits were also excised from the gel and digested with endoproteinase lys-C. The resulting peptides were separated by reverse phase HPLC with on-line diode array detection (1090M; HewlettPackard Co., Palo Alto, CA). Fractions containing aromatic residues were identified by their absorbance spectra and characterized by matrix-assisted, laser desorption, time-of-flight mass spectrometry (Lasermat; Finnigan MAT, Hemel Hempstead, Herts, UK) as described before (10). Selected peptides were then sequenced. Amyloid fibrils isolated from the spleen were also dissolved in guanidine hydrochloride, fractionated by gel filtration, and the single main subunit peak analyzed by electrospray mass spectrometry, all precisely as described previously (10).

apoAI gene studies. DNA was extracted from the proband's blood and two fragments of the apoAI gene, comprising the region encoding the $\mathrm{NH}_{2}$-terminal region of apoAI, were amplified by PCR and the nucleotide sequence determined, all as reported elsewhere (10). The $5^{\prime}$ end of exon 4 was abnormal, producing a PCR product of 361 bp as well as the normal 391-bp fragment. These were clearly distinguishable in a $3 \%$ gel of low melting point agarose and this procedure was used to screen the family for other carriers. The fragments were also excised from the gel, purified by Magiprep (Promega, Heidelberg, Germany) and sequenced (10).

Plasma apoAI analysis. Charge-variant apoAI was sought by isoelectric focusing in urea-agarose gel of dilapidated whole plasma, followed by pressure blotting and immunostaining with anti-apoAI antiserum, as described previously $(10,24)$.

Serum amyloid $P$ component $(S A P)^{1}$ scintigraphy. Scintigraphy after intravenous injection of radioiodinated pure human SAP was performed exactly as described previously $(25,26)$ except that the isotope iodine-131 was used instead of iodine-123. Although the image quality is not as good, the longer isotope half-life was necessary be-

1. Abbreviation used in this paper: $\mathrm{SAP}$, serum amyloid $\mathrm{P}$ component.

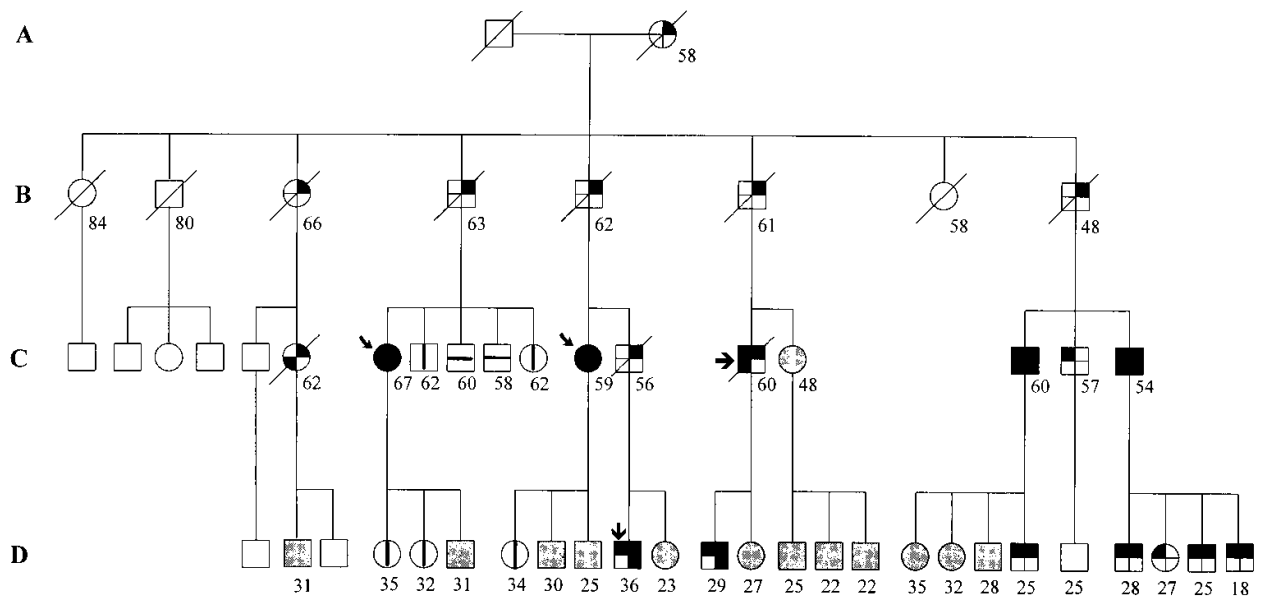

Figure 1. Family tree of the affected kindred. The proband is indicated by the arrow, $\rightarrow$, and the two female cousins in whom amyloid was first diagnosed are indicated by arrows, $\succ$. The individual marked $\downarrow$ had very low plasma apoAI and total HDL (Fig. 6) and massive hepatic amyloidosis (Fig. 8). The age of each individual, where known, is indicated below the symbol, circles for females and squares for males. Dead individuals are indicated by a diagonal line through the symbol. The symbols are filled to show the following information: $\square$ abnormal liver function tests; $\boxplus$ amyloid confirmed histologically; $\Xi$ SAP scintigraphy positive for amyloid;

$\boxplus$ apoAI deletion mutation present; $\boxminus$ normal liver function tests and SAP scan;

$\square$ normal liver function tests and genotype;

$\square$ normal liver function tests, SAP scan, and genotype.

Symbols or parts of symbols left blank indicate that tests have not been done and/or information is not available on these individuals. 
cause the SAP had to be labeled in London and flown to Barcelona for the patient studies.

\section{Results}

Clinical features. Affected individuals in generations A and B of the family (Fig. 1) died with liver failure between 48 and 66 yr of age. Apart from their abnormal liver function tests, no other clinical or pathological information is available, but it is likely that the female case in generation A was the source of the disease. Cases in generation $\mathrm{C}$ were found to have abnormal liver function tests at about 35-45 yr of age, but the patients all remained asymptomatic for the next 15-20 yr. During this phase, serum concentrations of alkaline phosphatase, transaminases, and $\gamma$-glutamyl transpeptidase were raised, but bilirubin was normal. There were no symptoms or signs of involvement of the kidneys, peripheral or autonomic nervous system, or any other tissues or organs. Liver function slowly deteriorated in all affected cases and in the proband there was an unusually rapid progression over $\sim 1$ yr to frank cholestasis, portal hypertension, hepatic encephalopathy, and death. Renal failure and proteinuria occurred during the terminal liver disease.

Percutaneous liver biopsies from four affected family members in generation $\mathrm{C}$ showed similar histology, with some preservation of overall structure, but most of the portal tracts replaced by large amyloid nodules, with some compressed arterioles and ductules at the periphery and a few foamy macrophages. Central veins and hepatic trabeculae appeared normal. A transjugular liver biopsy, from the patient who subsequently died and underwent postmortem examination, consisted of fragments of heavily amyloid-laden tissue with

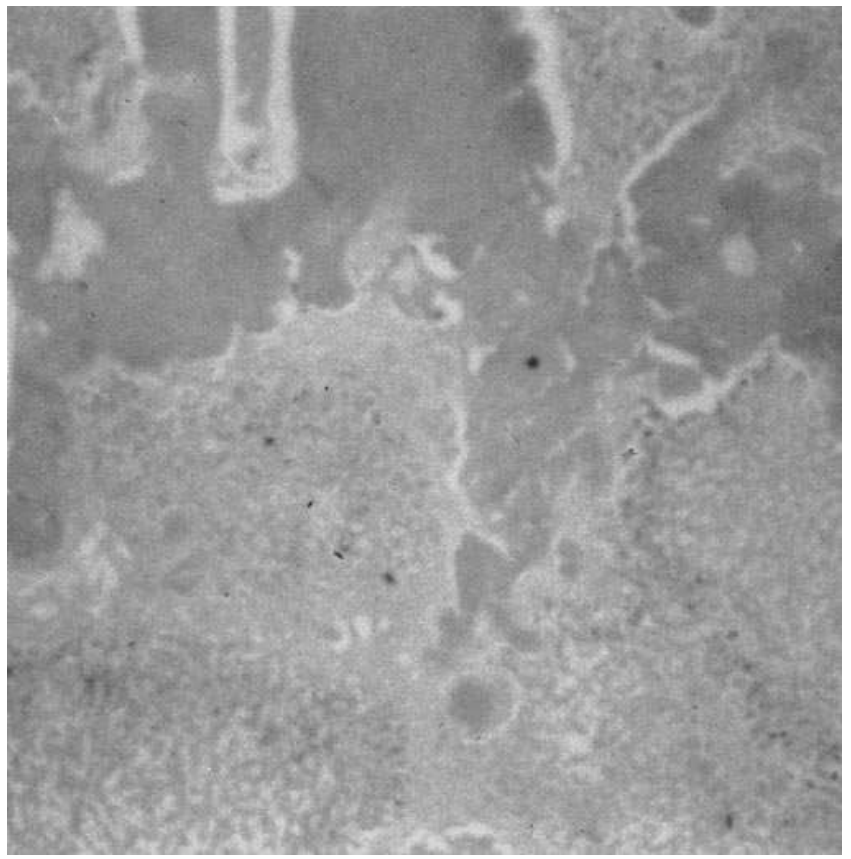

Figure 2. Cryostat section of unfixed liver from the autopsy of the proband, stained with Congo red and viewed in bright light, showing massive amyloid nodules among areas of cholestatic hepatic tissue. $(\times 100)$.
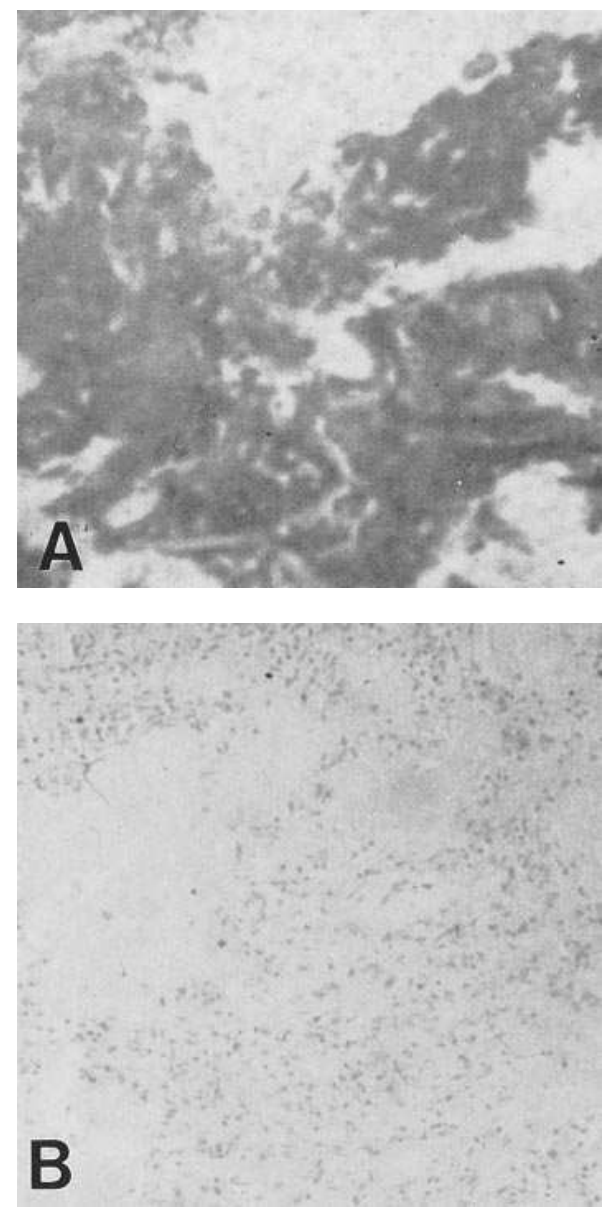

Figure 3. Sections of unfixed spleen from the autopsy of the proband, stained by the immunoperoxidase technique with antiserum to apoAI. $(A)$ Strong, positive staining of the massive amyloid deposits with unabsorbed antiserum. (B) Complete absence of staining with antiserum to apoAI that had been absorbed with pure human HDL $(\times 100)$.

conspicuous venous structures, but no identifiable hepatocytes or ductules.

At autopsy, his liver was markedly enlarged $(6,000 \mathrm{~g})$ with a granular capsule and small focal parenchymal areas of calcification. The right lobe was completely replaced by massive amyloid deposition and the left contained large confluent amyloid nodules among areas of cholestatic hepatic tissue (Fig. 2). The spleen was also large $(1,300 \mathrm{~g})$ with massive subcapsular amyloid and multiple nodular deposits within the parenchyma, unrelated to the white pulp (Fig. 3). The kidneys were small, with hard yellow nodular masses in the papillae, corresponding microscopically to diffuse interstitial amyloid deposition limited to the medulla, and associated with tubular atrophy. The renal cortex contained no amyloid; there was moderate atherosclerosis in the glomeruli and vessels. The heart was slightly enlarged and contained extensive interstitial amyloid but myocardial fibers were preserved. The adrenals were enlarged (right, $60 \mathrm{~g}$ and left, $35 \mathrm{~g}$ ) and massively infiltrated with amyloid, leaving only minimal islands of cortical cells. Both testes were also massively replaced with amyloid and showed marked atrophy of seminiferous tubules. There were perivenular amyloid deposits in the pituitary gland and its capsule and focal deposits were present in the thyroid, prostate, periprostatic sym- 

Val
Thr Trp
Mutant
CTGGG
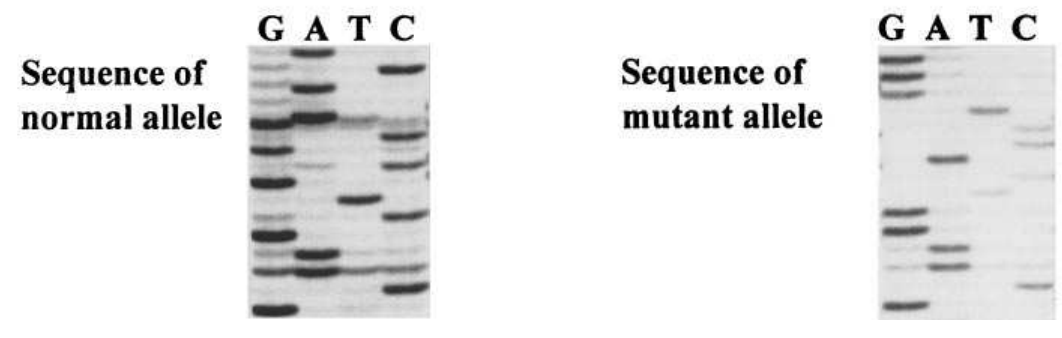

pathetic ganglia, bone, and articular cartilage. The lamina propria of the tongue contained a bandlike amyloid deposit, but the rest of the gut was spared, as were the lungs, bronchi, pancreas, lymph nodes, skin, and subcutaneous fat.

Identification of the amyloid fibril protein. Immunohistochemical staining of all the amyloidotic tissues obtained at autopsy was strongly and specifically positive with antibodies to apoAI (Fig. 3) and SAP, but was completely negative with antibodies to amyloid A protein, $\kappa$ and $\lambda$ immunoglobulin light chains, transthyretin, $\beta_{2}$-microglobulin, and lysozyme.

Characterization of the apoAI gene mutation. Sequencing of the apoAI gene from the deceased patient revealed that he was heterozygous for a mutation in exon 4 in which 35 nucleotides had been deleted from the wild-type sequence and $5 \mathrm{nu}$ cleotides inserted, maintaining the reading frame (Fig. 4). The mutation was readily demonstrable by gel analysis of the exon 4 PCR product (Fig. 5), and this test was used to screen all members of the family from whom samples could be obtained. The observed DNA changes encoded deletion of residues 60-71 of the mature wild-type amino acid sequence and their replacement by two new residues, ValThr. This predicted acquisition by the variant apoAI molecule of one additional positive charge, compared to wild-type apoAI.

Plasma lipid and lipoprotein studies. Among the family members from whom results were available, the plasma levels of apoAI and HDL were significantly lower in carriers of the mutation than in unaffected individuals (Table I), and were

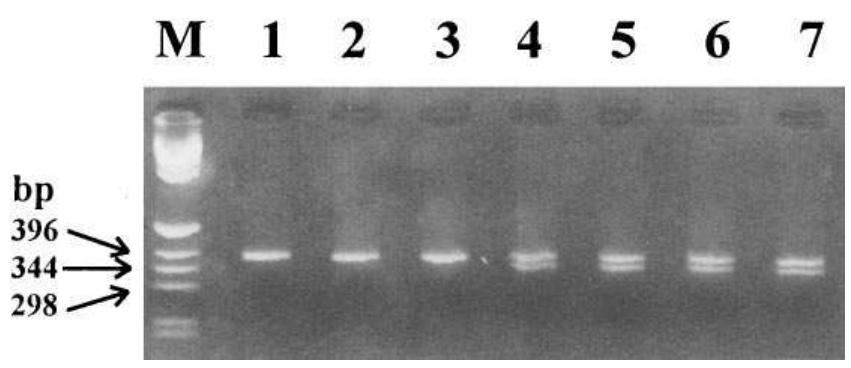

Figure 5. Agarose gel electrophoresis of the PCR product from the $5^{\prime}$ end of exon 4 of the apoAI gene. Affected individuals (lanes 4-7) yielded a product of $361 \mathrm{bp}$ in addition to the normal 391-bp fragment seen in unaffected family members (lanes 1-3). Markers of known length were run in lane $\mathrm{M}$. also lower than the normal range. There was a trend towards higher levels of LDL among the cases, although this did not achieve statistical significance, but the values for apoB, total cholesterol, and triglycerides were the same in the two groups. Subsequent measurements of plasma lipids and lipoproteins in other laboratories showed exactly the same pattern in further carriers and unaffected family members (data not shown).

A variant apoAI with one extra positive charge was detected in the plasma of carriers of the mutation (Fig. 6), but was significantly less abundant than wild-type apoAI, especially in one individual (Fig. 6, lane 1) with massive amyloidosis and a particularly low concentration of HDL and total apoAI ( $\sim 50 \%$ of the lower limit of normal). The variant was not detected in unaffected family members (Fig. 6).

Characterization of the amyloid fibril protein. Amyloid fibrils isolated from spleen, liver, and kidney tissue consisted predominantly of protein subunits running with apparent mass of $\sim 8-9 \mathrm{kD}$ in SDS-PAGE, just ahead of the $10-\mathrm{kD}$ subunit of amyloid fibrils from a case of apoAI Arg60 hereditary amyloi-

Table I. Plasma Lipid and Lipoprotein Levels in Relation to the ApoAI Gene Mutation

\begin{tabular}{lcccccc}
\hline & $\begin{array}{c}\text { HDL } \\
\text { cholesterol }\end{array}$ & ApoAI & $\begin{array}{c}\text { LDL } \\
\text { cholesterol }\end{array}$ & ApoB & $\begin{array}{c}\text { Total } \\
\text { cholesterol }\end{array}$ & $\begin{array}{c}\text { Total } \\
\text { triglycerides }\end{array}$ \\
\hline Carriers & & & & & & \\
$n$ & 11 & 11 & 11 & 11 & 13 & 13 \\
Mean & 28 & 90 & 172 & 137 & 212 & 109 \\
SD & 14 & 23 & 45 & 31 & 61 & 64 \\
Range & $12-48$ & $57-118$ & $93-240$ & $77-171$ & $106-315$ & $54-301$ \\
& $P<0.001$ & $P<0.001$ & NS & NS & NS & NS \\
Controls & & & & & & \\
$n$ & 11 & 11 & 11 & 11 & 14 & 14 \\
Mean & 67 & 164 & 136 & 130 & 222 & 106 \\
SD & 15 & 42 & 47 & 38 & 50 & 57 \\
Range & $49-98$ & $59-217$ & $68-215$ & $70-198$ & $149-322$ & $58-259$
\end{tabular}

The carriers tested comprised three females and ten males, mean age $41.9 \mathrm{yr}$, SD 17.6, range 18-67; the controls were eight female and six male family members, mean age $36.1 \mathrm{yr}$, SD 12.2 , range 23-60. The $P$ values denote significant differences between carriers and controls; NS, not significant. 


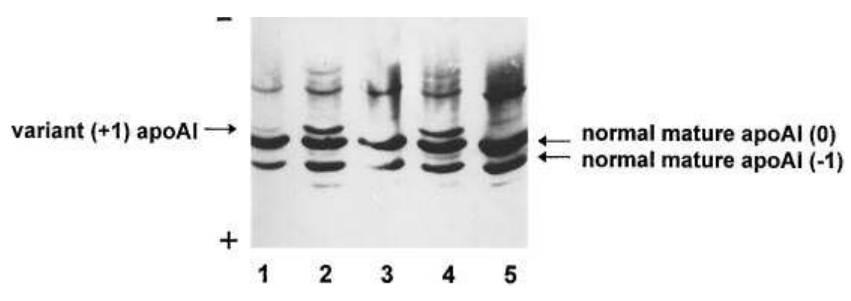

Figure 6. Immunoblot for apoAI of delipidated plasma after isoelectric focusing in agarose gel. Lanes 1,2 and 4, affected family members; lane 3 , unaffected family member; lane 5 , normal control. The most abundant isoform of normal mature wild-type apoAI is designated 0 and its deaminated product as -1 ; the variant apoAI encoded by the deletion/insertion mutation migrates as +1 . The sample in lane 1 was from the individual marked $\downarrow$ in Fig. 1 .

dosis (10) (Fig. 7). Immunoblotting (not shown) identified the subunits in the present case as fragments of apoAI and this was confirmed by automated amino acid sequencing, demonstrating the amino terminal sequence of mature human apoAI.

Electrospray mass spectrometric analysis of the purified spleen amyloid fibril subunits, separated by gel filtration, identified two dominant major species and a number of trace peaks (Table II). The main peaks corresponded precisely to the masses calculated for $\mathrm{NH}_{2}$-terminal fragments of mature variant apoAI encoded by the observed mutation, encompassing residues 1-83 and 1-92. The residues are numbered according to the wild-type sequence, but the masses are calculated to include deletion of wild-type positions $60-71$ and insertion of ValThr at this point. Almost all the minor peaks could be assigned to other $\mathrm{NH}_{2}$-terminal fragments of the variant sequence, and no species corresponding to fragments from wildtype apoAI were seen (Table II).

After endoproteinase lys-C digestion, no species corresponding to the peptide expected from wild-type apoAI, LREQLGPVTQEFWDNLEK, was found by HPLC and matrix-assisted, laser desorption, time-of-flight analysis. How-

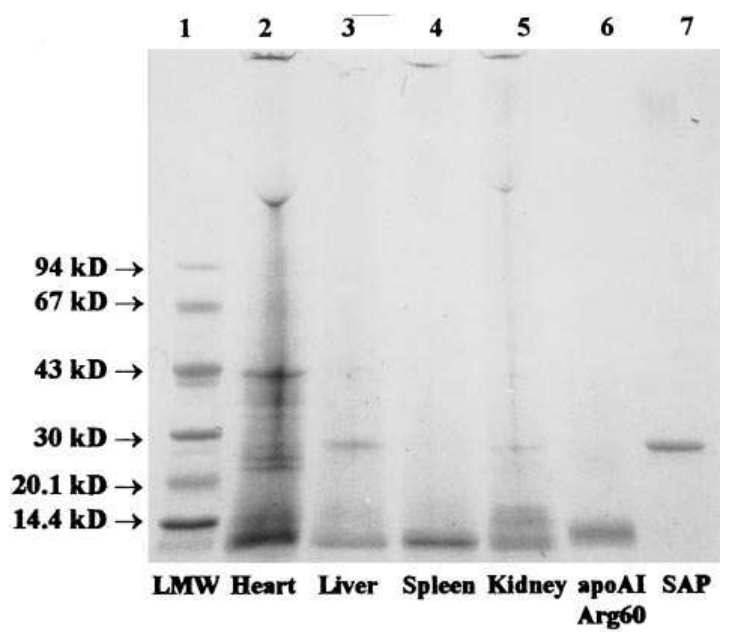

Figure 7. SDS 8-18\% PAGE analysis of amyloid fibrils extracted from various tissues of the proband. The main band in the fibrils from heart (lane 2), liver (lane 3), spleen (lane 4) and kidney (lane 5) ran ahead of the apoAI Arg60 fibril subunit (lane 6) (10). Marker proteins of known mass were run in lane 1 and isolated human serum amyloid P component, mass 25,462 D (45), in lane 7.
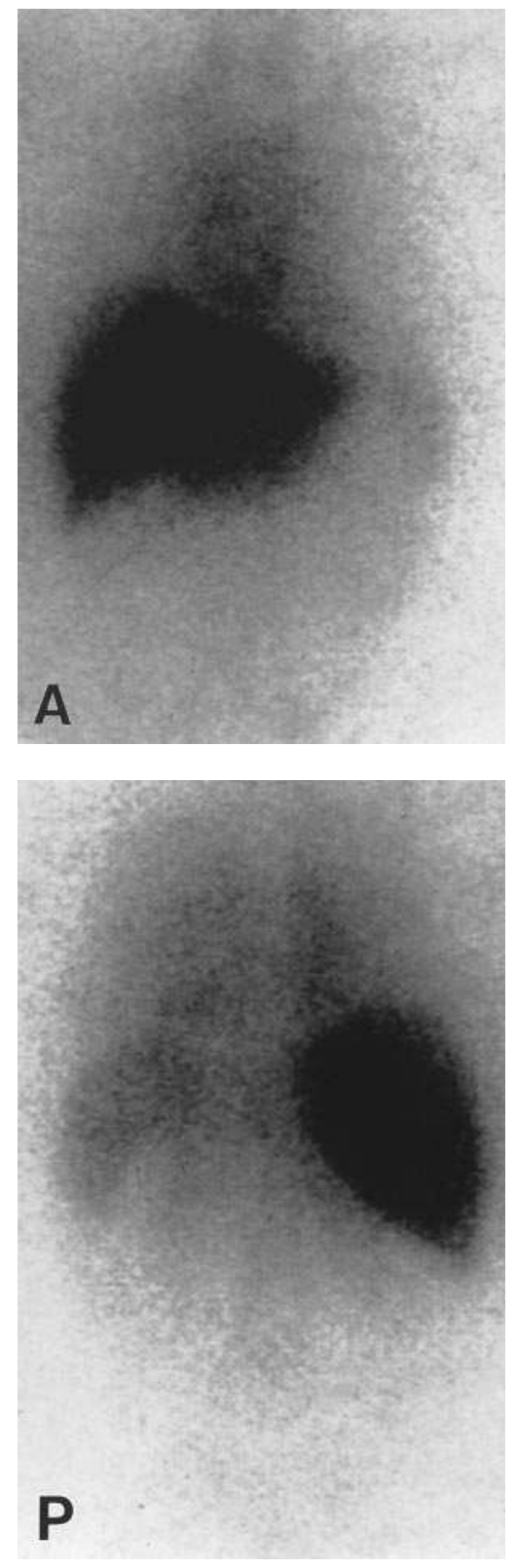

Figure 8. Anterior $(A)$ and posterior $(P)$ views of whole-body scintigrams taken $24 \mathrm{~h}$ after intravenous injection of ${ }^{131}$ I-labeled human SAP in the individual marked $\downarrow$ in Fig. 1. There is massive uptake of tracer in the liver and some in the spleen, but no significant retention elsewhere and very low blood-pool background, compatible with massive hepatic amyloidosis.

ever, a species with mass $1,004 \mathrm{D}$, corresponding to the peptide VTWDNLEK predicted from the sequence of the variant apoAI, was identified in each of four separate digests. This material yielded a single amino acid sequence of VTW in each case. It is not clear why sequencing was blocked after three residues, but cyclization of the adjacent aspartic acid and asparagine residues during the Edman chemistry cycles may have been responsible.

Radioiodinated SAP scintigraphy for amyloidosis. Scans were performed in 13 family members. Four individuals from generation $\mathrm{C}$ and three from generation $\mathrm{D}$, none of whom carried the apoAI gene mutation, showed no localization or retention of tracer. However, all carriers of the mutation, including four cases with amyloid confirmed histologically on liver biopsy, had abnormal scans with uptake of tracer in the liver in each case (Fig. 8), although there was considerable variation between patients. The weakest signal was observed in a bi- 
Table II. Electrospray Mass Spectrometry of Purified Subunits from Splenic ApoAI Amyloid Fibrils. Measured and Calculated Molecular Masses of Predicted Fragments

\begin{tabular}{|c|c|c|c|}
\hline & $\begin{array}{l}\text { Measured } \\
\text { mass (D) }\end{array}$ & Predicted apoAI fragment & $\begin{array}{l}\text { Calculated } \\
\text { mass (D) }\end{array}$ \\
\hline \multicolumn{4}{|c|}{ Major peaks } \\
\hline A & $8,332.7$ & $1-83$ & $8,332.2$ \\
\hline $\mathrm{B}$ & $9,438.8$ & 1-92 including methionine sulfoxide & $9,438.3$ \\
\hline \multicolumn{4}{|c|}{$\begin{array}{l}\text { Related } \\
\text { minor peaks }\end{array}$} \\
\hline BK & $8,353.7$ & $1-83+\mathrm{Na}^{+}$ & $8,355.2$ \\
\hline BW & $8,373.2$ & $1-83+\mathrm{K}^{+}$ & $8,372.2$ \\
\hline $\mathrm{BX}$ & $8,377.4$ & $1-83+2 \mathrm{Na}^{+}$ & $8,378.2$ \\
\hline $\mathrm{BJ}$ & $9,420.1$ & $1-92$ & $9,422.2$ \\
\hline $\mathrm{BN}$ & $9,462.1$ & $\begin{array}{c}1-92+\mathrm{K}^{+} \text {(or 1-92 including methionine } \\
\text { sulfoxide }+\mathrm{Na}^{+} \text {) }\end{array}$ & $\begin{array}{c}9,462.3 \\
(9,461.3)\end{array}$ \\
\hline CA & $9,471.1$ & $1-92+2 \mathrm{Na}^{+}$ & $9,468.3$ \\
\hline BV & $9,478.5$ & 1-92 including methionine sulfoxide $+\mathrm{K}^{+}$ & $9,478.3$ \\
\hline \multicolumn{4}{|c|}{$\begin{array}{l}\text { Other minor } \\
\text { peaks }\end{array}$} \\
\hline $\mathrm{BD}$ & $8,063.7$ & $1-81$ & $8,062.8$ \\
\hline BT & $8,196.2$ & $1-82+\mathrm{Na}^{+}$ & $8,199.0$ \\
\hline BQ & $8,590.7$ & $1-85$ & $8,589.4$ \\
\hline BL & $8,638.9$ & $1-85+2 \mathrm{Na}^{+}$ & $8,635.4$ \\
\hline $\mathrm{BH}$ & $8,951.9$ & 1-88 including methionine sulfoxide & $8,951.8$ \\
\hline BY & $9,306.5$ & 1-91 including methionine sulfoxide & $9,309.2$ \\
\hline BG & $9,538.4$ & 1-93 including methionine sulfoxide & $9,537.4$ \\
\hline BP & $9,559.4$ & 1-93 including methionine sulfoxide $+\mathrm{Na}^{+}$ & $9,560.4$ \\
\hline $\mathrm{CC}$ & $9,581.9$ & 1-93 including methionine sulfoxide $+2 \mathrm{Na}^{+}$ & $9,583.4$ \\
\hline $\mathrm{BO}$ & $9,601.8$ & $\begin{array}{c}1-93+2 \mathrm{~K}^{+} \text {(or 1-93 including methionine } \\
\left.\text { sulfoxide }+\mathrm{Na}^{+}+\mathrm{K}^{+}\right)\end{array}$ & $\begin{array}{c}9,601.4 \\
(9,600.4)\end{array}$ \\
\hline $\mathrm{BZ}$ & $9,642.7$ & $\begin{array}{l}1-93+3 \mathrm{~K}^{+} \text {(or 1-93 including methionine } \\
\text { sulfoxide }+\mathrm{Na}^{+}+2 \mathrm{~K}^{+} \text {) }\end{array}$ & $\begin{array}{c}9,641.4 \\
(9,640.4)\end{array}$ \\
\hline $\mathrm{BI}$ & $10,608.6$ & $1-102+2 \mathrm{Na}^{+}$ & $10,610.7$ \\
\hline $\mathrm{BE}$ & $10,706.3$ & $1-103+\mathrm{Na}^{+}$ & $10,702.7$ \\
\hline $\mathrm{BU}^{\prime}$ & $10,953.5$ & $1-105$ & $10,955.0$ \\
\hline $\mathrm{CD}$ & $11,582.6$ & $1-110$ including methionine sulfoxide $+\mathrm{K}^{+}$ & $11,582.7$ \\
\hline BS & $11,965.5$ & $1-113+2 \mathrm{Na}^{+}$ & $11,962.2$ \\
\hline
\end{tabular}

Residues numbered according to the wild-type sequence, but masses calculated to include the deletion of residues 60-71 and insertion of new residues ValThr at this position. Peaks A and B were overwhelmingly dominant. The other peaks were only traces by comparison, but all were assigned, as shown here, except two with masses 7,644.7 and 12,128.1 D.

opsy-positive 67-yr-old woman who remains asymptomatic 6 yr after discovery of abnormal liver function tests. This suggests that her amyloid load may be small and not increasing rapidly. In contrast, other patients, all of whom are also asymptomatic, had much more intense uptake in the liver and occasionally also the spleen, indicating a heavy visceral amyloid load, even at the much younger ages of 29 and $36 \mathrm{yr}$, and, possibly, predicting a more aggressive pattern of disease. No positive images of the kidneys, adrenals, or any other organs were observed in any case, possibly because of overwhelming uptake of tracer in the massive hepatic deposits.

\section{Discussion}

Affected members of the family described here had a unique phenotype of hereditary, nonneuropathic systemic amyloidosis that has not been reported previously and that was caused by the first deletion mutation to be associated with amyloidosis. Although at autopsy amyloid deposits were extremely widespread, the clinical presentation, ensuing illness, and death were all exclusively related to the massive hepatic involvement. In common with most other forms of systemic amyloidosis, there was an asymptomatic prodromal phase lasting for many years, with only biochemical evidence of disease. Nevertheless, liver biopsy or SAP scintigraphy demonstrated amyloid long before advent of clinical symptoms. Interestingly, SAP scintigraphy suggested anticipation, at least with respect to amyloid deposition, with three individuals in generation D aged between 29 and 36 having substantially more amyloid than four individuals in generation $C$ aged between 54 and 67 yr. Also, six of the seven generation $\mathrm{D}$ cases carrying the causative apoAI gene mutation already had abnormal liver func- 
tion tests at ages between 18 and 36; whereas, there was one 57yr-old carrier in generation $\mathrm{C}$ with no biochemical abnormality.

It remains to be seen whether clinical disease will also develop earlier and/or progress more rapidly in the youngest generation but, if it does, they may be candidates for orthotopic liver transplantation. This would both replace organ function and reduce, though not eliminate, production of the amyloidogenic apoAI-variant protein. Liver transplantation has been successful in hereditary transthyretin amyloidosis, eliminating the source of the variant amyloidogenic protein from the plasma and leading to clinical benefit in most patients and regression of amyloid deposits (27-29). Although apoAI is produced not only by the liver but also in the intestine and elsewhere $(30,31)$, a significant reduction in availability of the pathogenic variant might favorably reduce the rate of amyloid deposition in a disorder that already has a very long presymptomatic phase.

The concordance between the apoAI gene mutation discovered here, the presence of the corresponding charge variant apoAI protein in the plasma, the presence of amyloid in the tissues, the identification of apoAI as the amyloid fibril protein, and the clinical and/or biochemical signs established the mutation as the cause of the disease. It is highly penetrant and, among the 31 family members whose DNA we have been able to study, only 2 of the 13 carriers, aged 27 and 57, do not yet have any disturbance of liver function. Neither of these subjects has undergone either liver biopsy or SAP scintigraphy so the presence of amyloid deposits is not excluded.

The mechanisms by which any of the amyloidogenic variants of apoAI, including the present one, form amyloid fibrils are not known, but it is unlikely to be a coincidence that they all carry one extra positive charge on the $\mathrm{NH}_{2}$-terminal part of the molecule and that the fibrils in all analyzed cases are composed of this fragment. In amyloid fibrils of all types, the protein subunits are arranged in anti-parallel $\beta$-sheets lying with their long axes perpendicular to the fibril long axis $(32,33)$. Some intact native globular proteins, some fragments of larger proteins, and some synthetic peptides have a high propensity to aggregate and adopt this conformation; that is, they are amyloidogenic in vivo or in vitro (1). The point mutations that are responsible for the autosomal dominant hereditary amyloidoses evidently increase the amyloidogenicity of the affected proteins. In the case of lysozyme, gelsolin, fibrinogen, and cystatin $\mathrm{C}$, the wild-type molecule is not known to be amyloidogenic and either the whole or a fragment of the variant forms the fibrils. In the case of transthyretin and $\beta$-amyloid precursor protein, the wild-type molecule can be amyloidogenic in elderly individuals, but this is greatly enhanced for the variants. After the finding that wild-type apoAI causes senile pulmonary vascular amyloidosis in dogs $(34,35)$, it has lately been discovered that the frequent small amyloid deposits in the aortic wall of elderly human subjects, associated with atheromatous plaques, are also derived from wild-type apoAI (36).

ApoAI is thus an inherently amyloidogenic protein and this has been confirmed by the formation of amyloid fibrils from whole isolated apoAI in vitro (37), although in vivo the apoAI fibril subunits consist of $\mathrm{NH}_{2}$-terminal fragments. The variants may have enhanced amyloidogenicity because the substitutions destabilize the native structure, promoting fibrillogenic aggregation with proteolytic cleavage as a secondary phenomenon, or they may facilitate proteolytic cleavage of the native molecule to yield fibrillogenic fragments. Also, all amy- loid fibrils are tightly associated with polyanionic sulfated glycosaminoglycans in vivo $(38,39)$ that are thought to contribute to formation and/or stabilization of fibrils, and these interactions could be enhanced by the cationic nature of the amyloidogenic apoAI variants. Interestingly, a synthetic peptide corresponding to residues 9-20 of the wild-type apoAI sequence was amyloidogenic in vitro (36), although this does not necessarily relate to fibrillogenesis by the much larger fragments found in vivo. In the original case of Arg26 variant apoAI (Iowa), the main fragment consisted of residues 1-83 (16), while in human senile aortic amyloid, it was 1-69 (36), and in senile dogs 1-71 and 1-80 $(34,35)$, all determined only by amino acid sequencing. In our electrospray mass spectrometry study of the Arg60 variant, we found fragments 1-88, 92, 93, and 94 (10). In the present case, overwhelmingly the most abundant fragments were from position 1 to the residues corresponding to positions 83 and 92 in the wild-type, but including the deletion/insertion substitution that we have described here. In addition, we detected traces of fragments $1-81,82,85$, 88, 91, 93 102, 103, 105, 110, and 113. This level of precision cannot be achieved by sequencing without mass spectrometry, and it is likely that similar $\mathrm{COOH}$-terminal raggedness and heterogeneity is present in all cases. Either there is no particular, specifically amyloidogenic, cleavage point, or else the initial cleavage and/or subsequent $\mathrm{COOH}$-terminal clipping proceed as postfibrillogenic events (40).

Mass spectrometry also identified the frequent presence of sulfoxidation of Met86 in apoAI fibril subunits, both in the present case and in the Arg60 individual (10). While this might be an in vitro artifact generated during fibril isolation and protein purification, there is evidence that Met86 is relatively much more resistant to oxidation in vivo and in vitro than Met112 and Met148 in wild-type apoAI (41). The amyloidogenic substitutions, or, in the present case, deletion/insertion, $\mathrm{NH}_{2}$-terminal to Met86, might affect this property and thereby influence cleavage of apoAI and/or its association with HDL (42). Oxidation of apoAI can also enhance its polymerization (43).

In affected members of the present family, as in both the original Arg26 cases $(17,44)$ and the first Arg60 kindred (10), the plasma contained the expected charge variant form of apoAI, but at a significantly lower abundance than the wildtype protein in all individuals tested. This is compatible with the accelerated plasma clearance of the variant directly documented for apoAI Arg26 by Rader et al. (44), who also showed that clearance of normal apoAI was accelerated in carriers of this mutation who had subnormal plasma apoAI and HDL levels. However, after plasma clearance, the extravascular catabolism of variant apoAI was significantly slower than that of the wild-type, indicating sequestration, possibly in the amyloid deposits (44). Carriers in the Spanish family studied here also had subnormal plasma levels of both total HDL and of apoAI, and the individual with the lowest plasma concentration of variant compared to wild-type apoAI had massive hepatic and other amyloid deposits.

Identification of this new amyloidogenic variant extends the potential value of the apoAI model for studies of amyloidogenesis and enables informed testing and genetic counseling to be conducted in the affected family. Work on in vitro fibrillogenesis by apoAI is in progress and in the future, the effects of liver transplantation on survival, plasma apoAI levels and metabolism, and the natural history of extrahepatic amyloid deposits will be of considerable interest. 


\section{Acknowledgments}

We thank Alistair Sterling for technical assistance and Beth Sontrop for expert preparation of the manuscript.

This work was supported in part by Medical Research Council (UK) programme grant G7900510 to M.B. Pepys and P.N. Hawkins.

\section{References}

1. Pepys, M.B. 1994. Amyloidosis. In Samter's Immunologic Diseases, 5th ed. M.M. Frank, K.F. Austen, H.N. Claman, and E.R. Unanue, editors. Little, Brown and Co., Boston, MA. 637-655.

2. Selkoe, D.J. 1994. Alzheimer's disease: a central role for amyloid. J. Neurol. Neurosurg. Psychiatry. 53:438-447.

3. Selkoe, D.J. 1994. Normal and abnormal biology of the $\beta$-amyloid precursor protein. Аппи. Rev. Neurosci. 17:489-517.

4. Wattendorff, A.R., B. Frangione, W. Luyendijk, and G.T.A.M. Bots. 1995. Hereditary cerebral hemorrhage with amyloidosis, Dutch type (HCHWA-D): clinicopathological studies. J. Neurol. Neurosurg. Psychiatry. 58:699-705.

5. Jensson, O., A. Palsdottir, L. Thorsteinsson, and A. Arnason. 1989. The saga of cystatin $\mathrm{C}$ gene mutation causing amyloid angiopathy and brain hemorrhage-clinical genetics in Iceland. Clin. Genet. 36:368-377.

6. Levy, E., M. Haltia, I. Fernandez-Madrid, O. Koivunen, J. Ghiso, F. Prelli, and B. Frangione. 1990. Mutation in gelsolin gene in Finnish hereditary amyloidosis. J. Exp. Med. 172:1865-1867.

7. Maury, C.P.J., J. Kere, R. Tolvanen, and A. de la Chapelle. 1990. Finnish hereditary amyloidosis is caused by a single nucleotide substitution in the gelsolin gene. FEBS (Fed. Eur. Biochem. Soc.) Lett. 276:75-77.

8. Saraiva, M.J.M., P.P. Costa, and D.S. Goodman. 1993. Transthyretin and familial amyloidotic polyneuropathy. In The Molecular and Genetic Basis of Neurological Disease. R.N. Rosenberg, S.B. Prusiner, S. DiMauro, R.L. Barchi, and L.M. Kunkel, editors. Butterworth-Heinemann, Boston, MA. 889-894.

9. Jones, L.A., J.A. Harding, A.S. Cohen, and M. Skinner. 1991. New USA family has apolipoprotein AI (Arg26) variant. In Amyloid and Amyloidosis 1990. J.B. Natvig, Ø. Førre, G. Husby, A. Husebekk, B. Skogen, K. Sletten, and P. Westermark, editors. Kluwer Academic Publishers, Dordrecht, Netherlands. 385-388.

10. Soutar, A.K., P.N. Hawkins, D.M. Vigushin, G.A. Tennent, S.E. Booth, T. Hutton, O. Nguyen, N.F. Totty, T.G. Feest, J.J. Hsuan, et al. 1992. Apolipoprotein AI mutation Arg-60 causes autosomal dominant amyloidosis. Proc. Natl. Acad. Sci. USA. 89:7389-7393.

11. Vigushin, D.M., J. Gough, D. Allan, A. Alguacil, B. Penner, N.M. Pettigrew, G. Quinonez, K. Bernstein, S.E. Booth, D.R. Booth, et al. 1994. Familial nephropathic systemic amyloidosis caused by apolipoprotein AI variant Arg26. Q. J. Med. 87:149-154.

12. Booth, D.R., S.Y. Tan, S.E. Booth, J.J. Hsuan, N.F. Totty, O. Nguyen, T. Hutton, D.M. Vigushin, G.A. Tennent, W.L. Hutchinson, et al. 1995. A new apolipoprotein AI variant, Trp50Arg, causes hereditary amyloidosis. Q. J. Med. 88:695-702.

13. Pepys, M.B., P.N. Hawkins, D.R. Booth, D.M. Vigushin, G.A. Tennent, A.K. Soutar, N. Totty, O. Nguyen, C.C.F. Blake, C.J. Terry, et al. 1993. Human lysozyme gene mutations cause hereditary systemic amyloidosis. Nature (Lond.). 362:553-557.

14. Benson, M.D., J. Liepnieks, T. Uemichi, G. Wheeler, and R. Correa. 1993. Hereditary renal amyloidosis associated with a mutant fibrinogen $\alpha$-chain. Nature Genetics. 3:252-255.

15. Uemichi, T., J.J. Liepnieks, and M.D. Benson. 1994. Hereditary renal amyloidosis with a novel variant fibrinogen. J. Clin. Invest. 93:731-736.

16. Nichols, W.C., F.E. Dwulet, J. Liepnieks, and M.D. Benson. 1988. Variant apolipoprotein AI as a major constituent of a human hereditary amyloid. Biochem. Biophys. Res. Commun. 156:762-768.

17. Nichols, W.C., R.E. Gregg, H.B.J. Brewer, and M.D. Benson. 1990. A mutation in apolipoprotein A-I in the Iowa type of familial amyloidotic polyneuropathy. Genomics. 8:318-323.

18. Assmann, G., G. Schmitz, H. Funke, and A. von Eckardstein. 1990. Apolipoprotein A-I and HDL deficiency. Curr. Opin. Lipidol. 1:110-115.

19. Puchtler, H., F. Sweat, and M. Levine. 1962. On the binding of Congo red by amyloid. J. Histochem. Cytochem. 10:355-364.

20. Booth, D.R., S.Y. Tan, P.N. Hawkins, M.B. Pepys, and A. Frustaci. 1995. A novel variant of transthyretin, $59^{\text {Thr-Lys }}$, associated with autosomal dominant cardiac amyloidosis in an Italian family. Circulation. 91:962-967.

21. Pras, M., M. Schubert, D. Zucker-Franklin, A. Rimon, and E.C. Franklin. 1968. The characterization of soluble amyloid prepared in water. J. Clin. Invest. 47:924-933.

22. Tan, S.Y., I.E. Murdoch, T.J. Sullivan, J.E. Wright, O. Truong, J.J. Hsuan, P.N. Hawkins, and M.B. Pepys. 1994. Primary localized orbital amyloi- dosis composed of the immunoglobulin $\gamma$ heavy chain CH3 domain. Clin. Sci. (Lond.). 87:487-491.

23. Totty, N.F., M.D. Waterfield, and J.J. Hsuan. 1992. Accelerated highsensitivity microsequencing of proteins and peptides using a miniature reaction cartridge. Protein Sci. 1:1215-1224.

24. Menzel, H.-J., and G. Uterman. 1986. Apolipoprotein E phenotyping from serum by Western blotting. Electrophoresis. 7:492-495.

25. Hawkins, P.N., M.J. Myers, J.P. Lavender, and M.B. Pepys. 1988. Diagnostic radionuclide imaging of amyloid: biological targeting by circulating human serum amyloid P component. Lancet. i:1413-1418.

26. Hawkins, P.N., J.P. Lavender, and M.B. Pepys. 1990. Evaluation of systemic amyloidosis by scintigraphy with ${ }^{123}$ I-labeled serum amyloid $\mathrm{P}$ component. N. Engl. J. Med. 323:508-513.

27. Holmgren, G., L. Steen, J. Ekstedt, C.-G. Groth, B.-G. Ericzon, S. Eriksson, O. Andersen, I. Karlberg, G. Norden, M. Nakazato, et al. 1991. Biochemical effect of liver transplantation in two Swedish patients with familial amyloidotic polyneuropathy (FAP-met ${ }^{30}$ ). Clin. Genet. 40:242-246.

28. Holmgren, G., B.-G. Ericzon, C.-G. Groth, L. Steen, O. Suhr, O. Andersen, B.G. Wallin, A. Seymour, S. Richardson, P.N. Hawkins, et al. 1993. Clinical improvement and amyloid regression after liver transplantation in hereditary transthyretin amyloidosis. Lancet. 341:1113-1116.

29. Steen, L., G. Holmgren, O. Suhr, L. Wikström, C.-G. Groth, and B.-G. Ericzon. 1994. World-wide survey of liver transplantation in patients with familial amyloidotic polyneuropathy. Amyloid: Int. J. Exp. Clin. Invest. 1:138-142.

30. Zannis, V.I., F.S. Cole, C.L. Jackson, D.M. Kurnit, and S.K. Karathanasis. 1985. Distribution of apolipoprotein A-I, C-II, C-III, and E mRNA in fetal human tissue. Time-dependent induction of apolipoprotein E mRNA by cultures of human monocyte-macrophages. Biochemistry. 24:4450-4455.

31. Eggerman, T.L., J.M. Hoeg, M.S. Meng, A. Tombragel, D. Bojanovski, and H.B.J. Brewer. 1991. Differential tissue-specific expression of human apoA-I and apoA-II. J. Lipid Res. 32:821-828.

32. Glenner, G.G. 1980. Amyloid deposits and amyloidosis-the $\beta$-fibrilloses. I. N. Engl. J. Med. 302:1283-1292.

33. Blake, C.C.F. 1996. The molecular structure of familial amyloidotic polyneuropathy amyloid fibrils. In The Nature and Origin of Amyloid Fibrils. John Wiley \& Sons Inc. (Ciba Foundation Symposium 199), Chichester. In press.

34. Johnson, K.H., K. Sletten, D.W. Hayden, T.D. O'Brien, K.E. Roertgen, and P. Westermark. 1992. Pulmonary vascular amyloidosis in aged dogs. A new form of spontaneously occurring amyloidosis derived from apolipoprotein AI. Am. J. Pathol. 141:1013-1019.

35. Roertgen, K.E., E.M. Lund, T.D. O'Brien, P. Westermark, D.W. Hayden, and K.H. Johnson. 1995. Apolipoprotein AI-derived pulmonary vascular amyloid in aged dogs. Am. J. Pathol. 147:1311-1317.

36. Westermark, P., G. Mucchiano, T. Marthin, K.H. Johnson, and K. Sletten. 1995. Apolipoprotein A1-derived amyloid in human aortic atherosclerotic plaques. Am. J. Pathol. 147:1186-1192.

37. Wisniewski, T., A.A. Golabek, E. Kida, K.E. Wisniewski, and B. Frangione. 1995. Conformational mimicry in Alzheimer's disease. Role of apolipoproteins in amyloidogenesis. Am. J. Pathol. 147:238-244.

38. Snow, A.D., J. Willmer, and R. Kisilevsky. 1987. Sulfated glycosaminoglycans: a common constituent of all amyloids? Lab. Invest. 56:120-123.

39. Nelson, S.R., M. Lyon, J.T. Gallagher, E.A. Johnson, and M.B. Pepys. 1991. Isolation and characterization of the integral glycosaminoglycan constituents of human amyloid A and monoclonal light-chain amyloid fibrils. Biochem. J. 275:67-73.

40. Kisilevsky, R., S. Narindrasorasak, C. Tape, R. Tan, and L. Boudreau. 1994. During AA amyloidogenesis is proteolytic attack on serum amyloid A a pre- or post-fibrillogenic event? Amyloid: Int. J. Exp. Clin. Invest. 1:174-183.

41. von Eckardstein, A., M. Walter, H. Holz, A. Benninghoven, and G. Assmann. 1991. Site-specific methionine sulfoxide formation is the structure basis of chromatographic heterogeneity of apolipoproteins A-I, C-II, and C-III. J. Lipid Res. 32:1465-1476.

42. Parthasarathy, S., J. Barnett, and L.G. Fong. 1990. High density lipoprotein inhibits the oxidative modification of low-density lipoprotein. Biochem. Biophys. Acta. 1044:275-283.

43. Maziere, J.C., I. Myara, S. Salmon, M. Auclair, J. Haigle, R. Santus, and C. Maziere. 1993. Copper and malondialdehyde-induced modification of high density lipoprotein and parallel loss of lecithin cholesterol acyltransferase activation. Atherosclerosis. 104:213-219.

44. Rader, D.J., R.E. Gregg, M.S. Meng, J.R. Schaefer, L.A. Zech, M.D. Benson, and H.B.J. Brewer. 1992. In vivo metabolism of a mutant apolipoprotein, apoA-I $\mathrm{I}_{\text {Iowa }}$, associated with hypoalphalipoproteinemia and hereditary systemic amyloidosis. J. Lipid Res. 33:755-763.

45. Pepys, M.B., T.W. Rademacher, S. Amatayakul-Chantler, P. Williams, G.E. Noble, W.L. Hutchinson, P.N. Hawkins, S.R. Nelson, J.R. Gallimore, J. Herbert, et al. 1994. Human serum amyloid P component is an invariant constituent of amyloid deposits and has a uniquely homogeneous glycostructure. Proc. Natl. Acad. Sci. USA. 91:5602-5606. 